\title{
Influence of Displaced Clavicle Fracture toward Scapular Motion
}

\author{
Hermawan Nagar Rasyid \\ Department of Orthopaedics and Traumatology, Faculty of Medicine Universitas Padjadjaran, Dr. Hasan Sadikin Teaching \\ Hospital, Bandung, Indonesia \\ Email: hermawanphd@gmail.com
}

How to cite this paper: Rasyid, H.N. (2017) Influence of Displaced Clavicle Fracture toward Scapular Motion. Open Access Library Journal, 4: e3592. https://doi.org/10.4236/oalib.1103592

Received: April 10, 2017

Accepted: May 5, 2017

Published: May 8, 2017

Copyright (c) 2017 by author and Open Access Library Inc.

This work is licensed under the Creative Commons Attribution International License (CC BY 4.0).

http://creativecommons.org/licenses/by/4.0/

\section{(c) (†) Open Access}

\begin{abstract}
Displaced clavicle fracture can result in varying degrees of scapular motion and potentially to be winged scapula, which in the end of its journey will cause axioscapular dull-ache pain, which is often undiagnosed. The purpose of this study was to analyze the influence of clavicle fracture in different locations and its impact on the motion of scapula horizontally and vertically by measuring axioscapular distance. The inclusion criteria were patients suffering from closed displaced clavicle fracture. Motion of the scapula was observed radiologically. Statistical analysis using Chi-square test was performed. We may conclude that the lateral fracture of clavicle may have superior migration of the scapula and greater distance horizontally.
\end{abstract}

\section{Subject Areas}

Orthopedics

\section{Keywords}

Axioscapular Muscle, Dull-Ache Pain, Displaced Clavicle Fracture

\section{Introduction}

Stability of the scapulothoracic joint depends on coordinated activity of the surrounding musculature. When weakness or dysfunction of the scapular musculature is present, normal scapular positioning and mechanics may become altered [1] [2]. Abnormal motion of the scapula has variety of etiologies, and there are a number of case reports describing this condition following the non-operative treatment of displaced diaphysis fractures of the clavicle [3]. Clavicle fracture is one of the fractures which frequently occurs around $10 \%-15 \%$ of all fractures and generally in active younger individual, the incidence rate of diaphysis fractures is $80 \%$ of all fracture [4] [5] [6]. 
Duchenne [7] in 1867 described displacement of the scapula in detail in several neurologic conditions. Furthermore, Rasyid, et al., in 2000 proposed the sternoclaviculoscapular (SCS) linkage and described displacement of the scapula in several pathologic conditions of the shoulder including fracture of the clavicle and separation of the acromioclavicular (AC) joint. This author also made a report of two cases of winging of the scapula, and one was from a "neglected" fracture of the clavicle with $2-\mathrm{cm}$ of shortening [8]. Recently, a paper by Ristevski et al. in 2013, examined 18 patients with symptomatic clavicular malunion and evidence of scapular winging clinically [9]. Since the stability of the shoulder joint is maintained by the pull of muscles attached to the linkage, if the anterior component of the shoulder girdle disrupts, for instance a clavicle fracture occurred, it might alter the position of SCS linkage. Both muscular and gravitational forces acting on the fractured clavicle are significant and result in the typical deformity is seen after the fracture with the distal fragment is being translated inferiorly, anteriorly, medially, and rotated anteriorly. This alteration will be influencing the displacement of the scapula. Up to now, the axioscapular distance due to this shift has not yet been found in literatures.

The purpose of the study was to evaluate the impact of disconnection of SCS linkage by measuring the distance between body axis and the tip of inferior scapula in patients of clavicle fracture.

\section{Materials and Methods}

Prospective and descriptive methods were used in this study. We included 9 consecutive patients diagnosed with clavicle fractures admitted to Dr. Hasan Sadikin Hospital, Bandung, Indonesia from September 2015 to September 2016. The study protocol was approved by the Health Research Ethic Committee Dr. Hasan Sadikin Hospital, Bandung, Indonesia. The inclusion criteria was patient having clavicle fracture with shortening 1 to $2 \mathrm{~cm}$, while the exclusion criteria were patients with bilateral clavicle fracture, pathologic fracture, ribs fracture, stiff shoulder and neurological problems. Informed consent was obtained from patients prior to inclusion in the study. We divided the subjects into three groups based on the position of the fracture, with the groups originally divided by Allman [10] intoproximal (Group I) two patients, middle (Group II) three patients, and distal (Group III) four patients. The inferior tip of the scapula was marked with a small size of tin, prior to measurement. Axioscapular distance was measured in both shoulders in anatomical position using standardized anteroposterior (AP) radiographs. Through imaginary lines, the axioscapular distance with landmark from the spine process to inferior tip of the scapula in one horizontal and vertical dimension were measured using a caliper. These points were acquired bilaterally; therefore, relative scapula translation by comparing the affected side of clavicle fracture with the contralateral side could be obtained.

This research analyzed two variables, dependent and independent variables. Independent variable was closed fracture of the clavicle. Dependent variable was axioscapular distance, which measured through the imaginary line of the spinal 
process to the medial border of the scapula. Samples of homogeneity were conducted by the $t$ test. In order to analyze the correlation between clavicle fracture and motion of the scapula, a Chi-square test was performed. Results with a pvalue of less than 0.05 were considered statistically significant.

The patient presented here demonstrated anatomical abnormalities, and showed an indication for operative fixations with reason that the fracture was displaced more than $2 \mathrm{~cm}$ and separation of the right AC joint Allman Type-II [11]. The imaginary line of spine process (white dots line) to the inferior tip of scapula (white solid line) was performed to measure the axioscapular distance horizontally and vertically from both lines (black dots line).

\section{Results}

There were 6 males and 3 females suffering from clavicle fracture. The average age of the patients was 25.8 years, with the oldest being 51 and the youngest 13 . The right shoulder was involved in 7 patients and the left shoulder in 2 patients. The injury generally resulted from a direct blow to the shoulder due to a road traffic accident.

All 9 patients identified with evolved clavicle fracture had scapular motionhorizontally and vertically. Based on three parameters (see Table 1), the imaginary line from the spine process to inferior tip of body scapula and superior migration were measured, with the widest distance obtained in Group III, which appeared at a distance of $12.67 \mathrm{~cm}$, while the shortest distance in Group I was with a distance of $5.14 \mathrm{~cm}$. Superior migration of the inferior tip of body scapula occurred in Group III with a distance of $17 \mathrm{~cm}$, which was going up higher than in Group II and Group I, with a distance of $6.5 \mathrm{~cm}$, and $3.24 \mathrm{~cm}$, respectively. Overall, migration of the scapula could be seen towards inferior in Group I, while Group II and III were moving towards superior. Greater distance with significantly difference ( $\mathrm{p}=0.049$ ) was found in Group III compared to Group II. Significance difference was also identified in superior motion of the inferior tip of scapula ( $\mathrm{p}=0.011$ ) but was not at the distance of superior migration of the scapula $(\mathrm{p}=0.195)($ Table 2$)$.

\section{Discussion}

Scapula is a thin bone that serves as a site of muscle attachment for the upper

Table 1. Subject characteristics $(n=9)$.

\begin{tabular}{cccc}
\hline \multirow{2}{*}{ Characteristics } & \multicolumn{3}{c}{ Groups } \\
\cline { 2 - 4 } & I & II & III \\
\hline Sex & 2 & 2 & 3 \\
Male & $(-)$ & 1 & 1 \\
Female & & & \\
Age (years) & 29 & 20.3 & 28.5 \\
Average & $19-39$ & $18-22$ & $13-51$ \\
Range & & &
\end{tabular}


Table 2. Scapular migration related to clavicle fracture towards three parameters.

\begin{tabular}{ccccc}
\hline & \multicolumn{4}{c}{ Outcome (cm) } \\
\cline { 2 - 5 } Parameters & $\begin{array}{c}\text { Group I } \\
\mathrm{n}=2\end{array}$ & $\begin{array}{c}\text { Group II } \\
\mathrm{n}=3\end{array}$ & $\begin{array}{c}\text { Group III } \\
\mathrm{n}=4\end{array}$ & p-value \\
\hline $\begin{array}{c}\text { Axioscapular distance from } \\
\text { spine process to inferior tip of } \\
\text { body scapula. }\end{array}$ & 5.14 & 9.83 & 12.67 & $0.049^{*}$ \\
$\begin{array}{c}\text { Superior migration of inferior } \\
\text { tip of body scapula. }\end{array}$ & 3.24 & 6.5 & 17 & $0.0011^{*}$ \\
$\begin{array}{c}\text { Motion scapula compared to } \\
\text { normal side. }\end{array}$ & inferior & superior & superior & 0.195 \\
\hline
\end{tabular}

Note: ${ }^{\star}$ significance difference $(\mathrm{p}<0.05)$.

extremity and the thorax. There are 17 muscles having their origin or insertion on the scapula, making the essential link for coordinated upper-extremity activity [12]. Biomechanically, the scapula is markedly mobile and suspended on the chest wall by its musculature, its function is to stabilize the scapula to the posterior chest wall and provide power to the upper limb. All these muscles sometimes act at the same time and oppose each other at other times, but work together like a well-trained team to allow the arm to move. However, the scapula stability is permitted by muscles, joint capsule and strong ligaments to hold the relationship between the sternum and the upper extremity through the clavicle as a bony strut [8].

Disruption of the clavicle at any site by trauma leads to dysfunction of the muscles that move and support the shoulder complex and scapula. Therefore, instability of the scapula associated with the periscapular structures are to be exposed under stress, leading to move the scapula and create the scapula to be rotated and shifted [8] [13].

This pathogenesis is schematically drawn in Figure 1.

In the 9 cases presented here, most subjects consisted of 3 cases $(33.33 \%)$ of midshaft fracture, which was different from the literature which states that the majority of clavicle fractures (85\%) occur in the middle part since in a cross section, the narrowest and enveloping soft tissue structures are the most scarce [14] [15]. If the lever arm, in this case the clavicle does not work properly, this will lead to a disruption of stability of the scapula, such as clavicle fractures. The scapula will migrate to lateral and superior. Shortening of the clavicle occurred in all cases of group II, the degree of the shortening at the fracture site is very important to decide the treatment, as it has been reported in multiple studies, to be of prognostic significance, greater shortening more than 1.5 to $2 \mathrm{~cm}$ is associated with a worse prognosis [16]. In group II, the outer fragment remained attached to the scapula via the AC joint capsule. The scapula would move to lateral with inferior translation. This was due to the weight of the arm and pull of the pectoralis major muscle.

In group III, the scapula moved slightly superior, caused by the proximal 
fragment which was still stabilized to the coracoid process by the CC ligaments and to lateral fragment by the delto-trapezial fascia, therefore, group I showed minimal motion.

There was only one case of clavicle fracture lateral part in combination with AC joint dislocation (Figure 2) although open reduction of the fracture and transfixing of Kirschner wire through the AC joint could not correct the scapular migration completely, but, the axioscapular pain due to over stretching of the rhomboid muscle were relieved at the time of follow-up. Group I experienced a minimal shift migration superiorly and horizontally, whereas, the distance between the tip of the spine axis and the inferior border of the scapula was minimal. The fracture in this part was still limited by some ligaments which was attached to the first rib, such as the costoclavicular ligament.

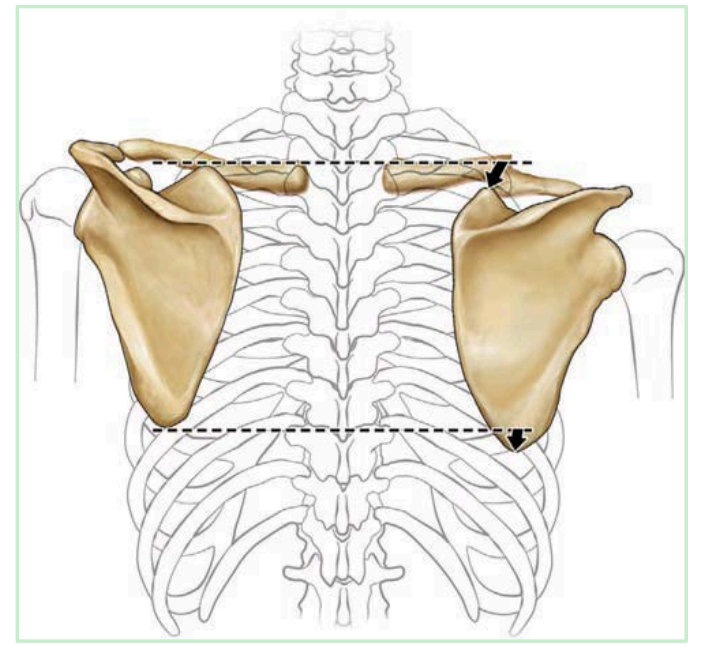

Figure 1. Schematic picture demonstrating the pathomechanism of scapular movement following clavicular fracture of the right clavicle (black arrow) [9].

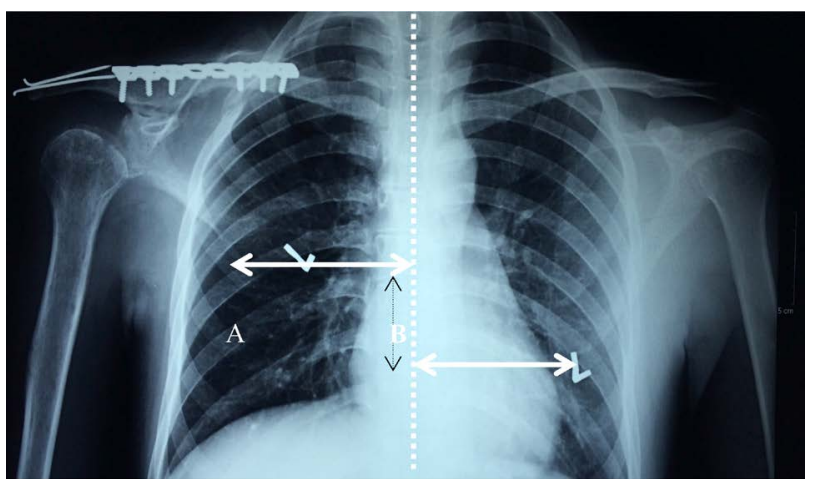

Figure 2. An AP radiograph of the bilateral shoulder in a 23-year-old man involved in a motor vehicle collision. It revealed a diaphysis of the right clavicle fracture with acromioclavicle (AC) joint separation. (A) Inferior tip of the right body scapula; (D) Inferior tip of the left body scapula; (E) Superior translation of the scapula; $(\mathrm{AB})$ Lateral displacement of the right scapula; (CD) Lateral displacement of the left scapula. 
Unrecognized, the scapular motion related to clavicle fracture may not be rare in the clinical practice. If the anterior component of the shoulder girdle is disrupted on any site by trauma, the periscapular structure is to be exposed under stress, leading to motion of the scapula horizontally and vertically. In this situation, restoration of the disrupted anatomy is essential.

This study has several limitations, including the sample size, accuracy of $\mathrm{x}$-ray taking and axioscapular distance measurements. The statistic results of the comparison between clavicle fracture groups and movement of the scapula do not show significant value due to the small amount of the subjects.

\section{Conclusion}

In conclusion, the results of the present study show that the pathogenesis of this scapular translation is considered the disruption of the anterior component of the shoulder girdle, which in all cases are displaced clavicle fractures. Lateral clavicle fracture will influence the upward motion of the scapula and shows greater distance horizontally, but does not show greater distance vertically.

\section{Acknowledgements}

Written informed consent was obtained from the patients for publication of this paper and for the use of any accompanying images.

\section{Conflict of Interest}

The authors report no conflict of interest concerning the findings specified in this paper.

\section{References}

[1] Voight, M.L. and Thomson, B.C. (2000) The Role of the Scapula in the Rehabilitation of Shoulder Injuries. Journal Athlete Training, 35, 364-372.

[2] Paine, R.M. and Voight, M.L. (1993) The Role of the Scapula. Journal of Orthopaedic \& Sports Physical Therapy, 18, 386-391.

https://doi.org/10.2519/jospt.1993.18.1.386

[3] McKee, R.C., Whelan, D.B., Schemitsch, E.H., et al. (2012) Operative versus Nonoperative Care of Displaced Midshaft Clavicle Fractures: A Meta-Analysis of Randomized Clinical Trials. The Journalof Bone and Joint Surgery, 94, 675-684. https://doi.org/10.2106/JBJS.J.01364

[4] Altamini, S.A., McKee, M.D. and Canadian Orthopaedic Trauma Society (2007) Nonoperative Treatment Compared with Plate Fixation of Displaced Midshaft Clavicular Fractures. Surgical technique. The Journalof Bone and Joint Surgery, 90, 1-8. https://doi.org/10.2106/JBJS.G.01336

[5] Nordqvist, A. and Peterson, C. (1994) The Incidence of Fractures of the Clavicle. Clinical Orthopedic and Related Research, 300, 127-132.

[6] Postacchini, F., Gumina, S., De Santis, P. and Albo, F. (2002) Epidemiology of Clavicle Fractures. Journal of Shoulder and Elbow Surgery, 11, 452-456.

https://doi.org/10.1067/mse.2002.126613

[7] Duchenne, G.B. (1959) Physiology of Motion. WB Saunders Co, Philadelphia, 3-41. 
[8] Rasyid, H.N., Nakajima, T. and Hamada, K. (2000) Winging of the Scapula Caused by Disruption of "sternoclaviculoscapular Linkage": Report of 2 Cases. Journal of Shoulder and Elbow Surgery, 9, 144-147.

[9] Ristevski, B., Hall, J.A., Pearce, D. et al. (2013) The Radiographic Quantification of Scapular Malalignment after Malunion of Displaced Clavicular Shaft Fractures. Journal of Shoulder and Elbow Surgery, 22, 240-246.

https://doi.org/10.1016/j.jse.2012.04.011

[10] Craig, E.V. (2006) Fractures of the Clavicle. In: Rockwood, C.A. and Green, D.P., Ed., Fractures in Adults, Lippincott Williams \& Wilkins, Philadelphia, 1216-1217.

[11] Allman, F.L. (1967) Fractures and Ligamentous Injuries of the Clavicle and Its Articulation. The Journal of Bone and Joint Surgery, 49A, 774-784.

https://doi.org/10.2106/00004623-196749040-00024

[12] Ianotti, J.P. and Williams, G.R. (2007) Disorders of the Shoulder, Diagnosis and Management. 2nd Edition, Lippincott Williams \& Wilkins, Philadelphia.

[13] Paine, R.M. and Voight, M.L. (2003) The Role of the Scapula. International Journal of Sports Physical Therapy, 8, 617-629.

[14] Robinson, C.M., Court-Brown, C.M., McQueen, M.M., et al. (2004) Estimating the Risk of Nonunion Following Nonoperative Treatment of a Clavicle Fracture. The Journal of Bone and Joint Surgery, 86, 1359-1365. https://doi.org/10.2106/00004623-200407000-00002

[15] McKee, M.D. (2015) Clavicle Fractures. In: Rockwood, C.A. and Green, D.P., Eds., Fracture in Adults, Lippincott Company, Philadelphia, 1427-1474.

[16] Smekal, V., Deml, C., Irenberger, A., et al. (2008) Length Determination in Midshaft Clavicle Fractures: Validation of Measurement. Journal of Orthopaedic Trauma, 22, 458-462. https://doi.org/10.1097/BOT.0b013e318178d97d

Submit or recommend next manuscript to OALib Journal and we will provide best service for you:

- Publication frequency: Monthly

- 9 subject areas of science, technology and medicine

- Fair and rigorous peer-review system

- Fast publication process

- Article promotion in various social networking sites (LinkedIn, Facebook, Twitter, etc.)

- Maximum dissemination of your research work

Submit Your Paper Online: Click Here to Submit

Or Contact service@oalib.com 